\title{
Operating room efficiency in a low resource setting: a pilot study from a large tertiary referral center in Ethiopia
}

Samuel Negash ${ }^{1 *}\left(\mathbb{D}\right.$, Endale Anberber ${ }^{1}$, Blen Ayele ${ }^{2}$, Zeweter Ashebir², Ananya Abate ${ }^{2}$, Senait Bitew ${ }^{3}$, Miliard Derbew ${ }^{1,3}$, Thomas G. Weiser ${ }^{3,4,5}$, Nichole Starr ${ }^{3,6}$ and Tihitena Negussie Mammo 1,3

\begin{abstract}
Background: The operating room (OR) is one of the most expensive areas of a hospital, requiring large capital and recurring investments, and necessitating efficient throughput to reduce costs per patient encounter. On top of increasing costs, inefficient utilization of operating rooms results in prolonged waiting lists, high rate of cancellation, frustration of OR personnel as well as increased anxiety that negatively impacts the health of patients. This problem is magnified in developing countries, where there is a high unmet surgical need. However, no system currently exists to assess operating room utilization in Ethiopia.
\end{abstract}

Methodology: A prospective study was conducted over a period of 3 months (May 1 to July 31, 2019) in a tertiary hospital. Surgical case start time, end time, room turnover time, cancellations and reason for cancellation were observed to evaluate the efficiency of eight operating rooms.

Results: A total of 933 elective procedures were observed during the study period. Of these, 246 were cancelled, yielding a cancellation rate of $35.8 \%$. The most common reasons for cancellation were related to lack of OR time and patient preparation (8.7\% and $7.7 \%$ respectively). Shortage of facilities (instrument, blood, ICU bed) were causes of cancelation in 7.7\%. Start time was delayed in $93.4 \%$ (mean $8: 56 \mathrm{am} \pm 52 \mathrm{~min}$ ) of cases. Last case completion time was early in $47.9 \%$ and delayed in 20.6\% (mean 2:54 pm $\pm 156 \mathrm{~min}$ ). Turnover time was prolonged in 34.5\% (mean $25 \mathrm{~min} \pm 49 \mathrm{~min}$ ). Total operating room utilization ranged from $10.5 \%$ to $174 \%$. Operating rooms were underutilized in $42.7 \%$ while overutilization was found in $14.6 \%$.

Conclusion: We found a high cancellation rate, most attributable to late start times leading to delays for the remainder of cases, and lack of preoperative patient preparation. In a setting with a high unmet burden of surgical disease, OR efficiency must be maximized with improved patient evaluation workflows, adequate OR staffing and commitment to punctual start times. We recommend future quality improvement projects focusing on these areas to increase OR efficiency.

Keywords: Operating room, Efficiency, Utilization, Cancellation rate, Turnover time, Start time delay

*Correspondence: negashsamie@gmail.com

${ }^{1}$ Department of Surgery, Addis Ababa University, Addis Ababa, Ethiopia

Full list of author information is available at the end of the article

\section{Background}

Operating rooms (ORs) are some of the most important areas of hospitals that have significant impact on the overall picture of a hospital's performance $[1,2]$. Running an operating room is capital and labor intensive [1-4]. When OR utilization is inefficient, it leads to wastage original author(s) and the source, provide a link to the Creative Commons licence, and indicate if changes were made. The images or other third party material in this article are included in the article's Creative Commons licence, unless indicated otherwise in a credit line to the material. If material is not included in the article's Creative Commons licence and your intended use is not permitted by statutory regulation or exceeds the permitted use, you will need to obtain permission directly from the copyright holder. To view a copy of this licence, visit http://creativecommons.org/licenses/by/4.0/. The Creative Commons Public Domain Dedication waiver (http://creativeco mmons.org/publicdomain/zero/1.0/) applies to the data made available in this article, unless otherwise stated in a credit line to the data. 
of time and human resources, higher costs and fewer patients treated than planned. This constellation of issues results in financial losses as well as decreased patient satisfaction [5].

Furthermore, recent publications regarding global surgery have highlighted the high unmet need for safe surgery in developing countries. Lack of personnel and facility are contributors to this problem [6, 7]. However, it is also our observation that many existing operating rooms in our country are underutilized. In this case, increasing efficiency can reduce patient wait times without incurring additional cost [8].

Thus far, there is scant literature assessing OR efficiency in different areas of Ethiopia [8-11]. Additionally, all of the studies assessed focused solely on the cancellation rate. Looking into this parameter alone may lead to wrong conclusion and lack of improved outcome after intervention. Other factors affecting performance such as late starts, early finishes, long time between cases and mismatch of scheduled sessions with existing capacity were not considered but have a potentially large impact on the OR efficiency.

The aim of this study was to evaluate all five indicators of OR utilization: start time, finish time turnover time and total daily utilization, together with cancellation rate. This evaluation aimed to provide a comprehensive assessment of the overall OR efficiency and inform the subsequent planning of interventions. In addition, we hope to encourage the culture of continuous monitoring of efficiency in operatinng rooms across Ethiopia.

\section{Methodology}

This study was undertaken at Tikur Anbessa Specialized Hospital (TASH), in Addis Ababa, Ethiopia. TASH is the main teaching hospital of the country and provides many specialized clinical services that are not available in other public or private institutions. TASH is also the largest hospital in the country with a capacity of more than 700 beds. It has 12 operating rooms which is more than any other hospital in the country.

The design was a descriptive observational study. Data was collected from eight operating rooms over a period of three months (May 1 - July 31, 2019). Surgical specialties utilizing these operating rooms included otolaryngology, urology, cardiothoracic surgery, neurosurgery, pediatric surgery, general surgery and obstetrics/gynecology. Emergency operating rooms were excluded because they function without a schedule.

Based on existing literature $[12,13]$ and considering standard working hours to be $8 \mathrm{~h}$ per day starting at 8:00 am; we set standards the five indicators in our hospital (Table 1).

A data collection tool was designed by the investigators and pretested with a subset of cases for ease of administration and clarity of terminology. Data were collected by trained operating room nurses. Data cleaning and analysis was done using SPSS version 23. Chi-squared tests were used to report outcomes and two-sided significance level was set to be $0.05(5 \%)$. Ethical clearance was obtained from the research committee at the Department of Surgery, Addis Ababa University College of Health Sciences.

\section{Results}

A total of 687 operations were performed during the study period. Most of the time, two procedures were performed in a room per day (39.6\%), followed by a single procedure per day (36.5\%). Additional procedures were sometimes performed with three procedures per day

Table 1 The five indicators of OR efficiency

Start time

Turnover time

Finish time

OR utilization

Cancellation rate
Time the first patient of the day entered the operating room Late start = later than 15 min of scheduled time (after 8:15 am)

Time between one patient leaving the operating table and another patient entering (time for cleaning and preparing for next patient)

Long turnover $=$ time in between cases $>25 \mathrm{~min}$

Time the last patient of the day left the operating room Early finish time $=1 \mathrm{~h}$ before working hours (before 3:00 pm) Late finish time $=1 \mathrm{~h}$ after working hours (after 5:00 pm)

Proportion of time within the working hours in which a patient was in the operating room (does not include turnover time) Low utilization $=$ less than $<75 \%$ of working hour utilized $(<6 \mathrm{~h})$

Over utilization $=$ more than allocated working hours $(>100 \%$ />8 h)

Day of surgery cancellation

High cancellation rate $=$ greater than $5 \%$ 
Table 2 Reasons for cancellation

\begin{tabular}{ll}
\hline Reasons & $\boldsymbol{N}(\%)$ \\
\hline Lack of OR time & $82(8.7 \%)$ \\
Patient medically unfit for surgery & $72(7.7 \%)$ \\
Lack of ICU bed & $41(4.4 \%)$ \\
Lack of instruments & $16(1.7 \%)$ \\
Lack of blood & $15(1.6 \%)$ \\
Other & $23(2.5 \%)$ \\
Total & $246(35.8 \%)$ \\
\hline
\end{tabular}

in $16.4 \%$ and 4 procedures per day in $7.4 \%$ of operating rooms.

Total number of scheduled elective cases were 933 of which 246 were cancelled, yielding a cancellation rate of $35.8 \%$. The most common cause of cancellation was lack of OR time (workday ending before scheduled cases are finished). This was followed by issues related to perioperative patient preparation. Others were institutional factors, of which the lack of an ICU bed was the most common (Table 2).

The start time ranged from 7:45 am to 9:30 am. Mean start time was 8:56 am $\pm 52 \mathrm{~min}$. The start time was delayed past 8:15am in $93.4 \%$ of the cases. In addition, the time of start for the first surgery (incision time) ranged from 8:00 am to 10:18 am with mean 9:41 am \pm 60 min.

Turnover time ranged from $3 \mathrm{~min}$ to $2 \mathrm{~h}$. Mean was $25 \mathrm{~min} \pm 49 \mathrm{~min}$. Turnover time was prolonged in $34.5 \%$. The finish time ranged from 8:45 am to 11:12 pm. Mean finish time was $2: 54 \mathrm{pm} \pm 156 \mathrm{~min}$. The end time was early in $47.9 \%$ and delayed in $27.8 \%$.

Mean number of surgeries per day was $1.9 \pm 0.9$. Mean time spent on surgery per day was $4 \mathrm{~h} \pm 140 \mathrm{~min}$. Remaining time was occupied by anesthesia preparation and intubation ( $1 \mathrm{~h}$ and $23 \mathrm{~min} \pm 132 \mathrm{~min}$ ), extubating and transfer of patients $(42 \min \pm 34 \mathrm{~min})$, turnovers $(40 \mathrm{~min} \pm 38 \mathrm{~min}$ ). Total operating room utilization ranged from $10.5 \%$ to $174 \%$. It was underutilized $(<6 \mathrm{~h})$ in $42.7 \%$ of the cases while overutilization $(>8 \mathrm{~h})$ was found in $14.6 \%$ (Table 3 ).

\section{Discussion}

An efficient operating room should start early, finish on time, allocate minimal time for preparation between procedures and have a low rate of cancellation. Poor utilization of the operating room leads to wastage and drains resources which is very valuable in low income countries with a high unmet need for surgery $[14,15]$. Additionally, it results in patient dissatisfaction and staff demoralization $[14,16]$.
Table 3 Summary of the parameters of OR efficiency and comparison to predefined standards

\begin{tabular}{lll}
\hline Parameters & Result & $\begin{array}{l}\text { Comparison to } \\
\text { Predefined criteria }\end{array}$ \\
\hline Start time & $8: 56 \mathrm{am} \pm 52 \mathrm{~min}$ & $93.4 \%$ delayed \\
Turnover time & $25 \mathrm{~min} \pm 49 \mathrm{~min}$ & $34.5 \%$ delayed \\
Finish time & $2: 54 \mathrm{pm} \pm 156 \mathrm{~min}$ & $47.9 \%$ early \\
OR utilization & $10.5 \%-174 \%$ & $27.8 \%$ delayed \\
& & $42.7 \%$ under utilized \\
Cancelation rate & $35.8 \%$ & $14.6 \%$ over utilized \\
\end{tabular}

In our study, the cancellation rate was $35.8 \%$ which is similar to the previous study on elective surgery cancellation in the same hospital (33.9\%) [10]. Studies done in other major teaching hospitals in Ethiopia also had similar findings with the cancelation rate at Gondar University Hospital 33.1\% [11] Hawassa Gondar University Hospital 31.6\% [9], and Jimma University Hospital $23 \%$ [8]. The reasons for cancellation were also similarly related to shortage of time (over scheduling) and inadequate patient preparation. This is in contradiction to the belief that higher rate of cancellation in low income countries is unavoidable (due to resource constraints) [17].

We found turnover time was $25 \min \pm 49$ min with delay in $34.5 \%$. This is an acceptable figure considering the best performing operating rooms report a turnover time less than 25 min [13]. Furthermore, we have found the number of procedures done per OR each day is low (76\% perform either 1 or 2 procedures per OR per day). Therefore, attempting to decrease turnover time would likely not have significant impact in this setting.

The start time was delayed in $93.4 \%$ of the cases. This may be the most important parameter as it decides the day's surgical activity [18]. Downstream effect of the late starts can also be the cause for frequent cancellations observed in our study due to lack of OR time. Many institutions have used different strategies to improve starting time [18-20]. To implement these in our setting we need further data evaluating the reasons for delay of the first case. In addition, we found frequent delays between patient entering operating room and start of surgery (43 $\mathrm{min} \pm 40 \mathrm{~min})$. This needs further evaluation of anesthesia induction and surgical preparation practice.

Assessment of the total OR utilization found a wide range with a majority (57.3\%) either underutilized or overutilized. The finish time was very early or late in $75.7 \%$. Early finish times can be improved by decreasing the cancellation rate, especially those related to patient preparation. Overutilization and late finish times also 
need to be corrected as it leads to staff burnout and overtime costs [21]. Having a late start time can again be an important factor cascading to delay in the finish time.

\section{Conclusion}

Overall, this study found our operating rooms are inefficient, with high cancelation rates that can be attributed to delayed start times, short working days and inadequate patient preparation. This is in contrary to the belief that inefficiency in operating rooms of low-income countries is related to lack of infrastructure. While the physical space may not be a limiting factor, human resources to adequately staff ORs and meet overtime needs, and culture change around earlier start times may ameliorate some of these challenges. In a setting such as Ethiopia where there is a large unmet burden of surgical disease, future interventions to improve the function of our operating rooms should be focused on these two areas.

\section{Abbreviations}

OR: Operating room; TASH: Tikur Anbessa Specialized Hospital.

\section{Acknowledgements}

We would like to express our gratitude to all staff working in the operating room at TASH.

\section{Authors' contributions}

EA designed the methodology and coded data. SN performed data analysis and drafted the manuscript. All authors read and approved the final manuscript.

\section{Funding}

This study did not receive funding.

\section{Availability of data and materials}

The datasets during and/or analysed during the current study available from the corresponding author on reasonable request.

\section{Declarations}

\section{Ethics approval and consent to participate}

Ethical clearance was obtained from the research committee at the Department of Surgery, Addis Ababa University College of Health Sciences.

\section{Consent for publication}

Not applicable

\section{Competing interests}

The authors declare that they have no competing interests.

\section{Author details}

'Department of Surgery, Addis Ababa University, Addis Ababa, Ethiopia. ${ }^{2}$ Department of Anesthesia, Addis Ababa University, Addis Ababa, Ethiopia. ${ }^{3}$ Lifebox Foundation, London, UK. ${ }^{4}$ Department of Surgery, University of Edinburgh, Edinburgh, UK. ${ }^{5}$ Department of Surgery, Stanford University, Stanford, USA. ${ }^{6}$ Department of Surgery, University of California San Francisco, San Francisco, USA.

Received: 24 October 2021 Accepted: 13 December 2021 Published online: 07 January 2022
References

1. Al-Saffar A. Enhancing Operating Theatre Efficiency of Private Hospital in Kuwait; Business Management Approach [Masters dissertation]. Dublin R Coll Surg Irel. 2011;186.

2. Scotland AC for. Full House- Theatre Utilisation in Scottish Hospitals. 1999.

3. Cymru A. Operating Theatres: A Summary of Local Audit Findings | Audit Wales. 2016. ([cited 2021 Oct 4]; Available from: https://www.audit.wales/ publication/operating-theatres-summary-local-audit-findings-0).

4. Cardoen B, Demeulemeester E, Beliën J. Operating room planning and scheduling: A literature review. Eur J Oper Res. 2010;201(3):921-32.

5. Street W. Operation theater efficiency. Off Audit Gen West Aust. 2015;58.

6. Derbew M. Pediatric surgery in Eastern Africa: The unmet need. J Pediatr Surg. 2019;54(1):21-6.

7. Global Surgery 2030: evidence and solutions for achieving health, welfare, and economic development. The Lancet Commissons. 2015 [cited 2021 Oct 4]; Available from: https://www.thelancet.com/journals/lancet/ article/PIIS0140-6736(15)60160-X/fulltext?dgcid=recommender_referral_ trendmd

8. Haile M, Desalegn N. Prospective study of proportions and causes of cancellation of surgical operations at Jimma University Teaching Hospital, Ethiopia. Int J Anesth Res. 2015;3(2):87-90.

9. Desta M, Manaye A, Tefera A, Worku A, Wale A, Mebrat A, et al. Incidence and causes of cancellations of elective operation on the intended day of surgery at a tertiary referral academic medical center in Ethiopia. Patient Saf Surg. 2018;12(1):1-6.

10. Ayele A, Weldeyohannes M, Tekalegn Y. Magnitude and reasons of surgical case cancellation at a specialized Hospital in Ethiopia. J Anesth Clin Res. 2019;10(927):2.

11. Nigatu YA, Aytolign HA. Cause and incidence of Cancellation of elective surgeries at Gondar University hospital, Ethiopia. 2020.

12. Fixler T, Wright JG. Identification and use of operating room efficiency indicators: the problem of definition. Can J Surg. 2013;56(4):224-6.

13. Nuhu SI, Embu HY, Atteh FD, Kokong D, Aliyu HA. Theatre start and turnover times in a developing country. Highl Med Res J. 2020;20(1):51-5.

14. Schuster M, Neumann C, Neumann K, Braun J, Geldner G, Martin J, et al. The Effect of Hospital Size and Surgical Service on Case Cancellation in Elective Surgery: Results from a Prospective Multicenter Study. Anesth Analg. 2011;113(3):578-85.

15. Stavrou G, Panidis S, Tsouskas J, Tsaousi G, Kotzampassi K. An audit of operating room time utilization in a teaching hospital: is there a place for improvement? Int Sch Res Not. 2014;2014:431740.

16. Heslin MJ, Doster BE, Daily SL, Waldrum MR, Boudreaux AM, Smith AB, et al. Durable Improvements in Efficiency, Safety, and Satisfaction in the Operating Room. J Am Coll Surg. 2008;206(5):1083-9.

17. Prin M, Eaton J, Mtalimanja O, Charles A. High Elective Surgery Cancellation Rate in Malawi Primarily Due to Infrastructural Limitations. World J Surg. 2018;42(6):1597-602.

18. Pashankar DS, Zhao AM, Bathrick R, Taylor C, Boules H, Cowles RA, et al. A Quality Improvement Project to Improve First Case On-time Starts in the Pediatric Operating Room. Pediatr Qual Saf. 2020;5(4):e305.

19. Shippert RD. A Study of Time-Dependent Operating Room Fees and How to save $\$ 100000$ by Using Time-Saving Products. Am J Cosmet Surg. 2005:22(1):25-34.

20. Wright JG, Roche A, Khoury AE. Improving on-time surgical starts in an operating room. Can J Surg. 2010;53(3):167-70.

21. Overutilization and underutilization of operating rooms - insights from behavioral health care operations management. Health Care Manag Sci. 2017;20:115-28.

\section{Publisher's Note}

Springer Nature remains neutral with regard to jurisdictional claims in published maps and institutional affiliations. 